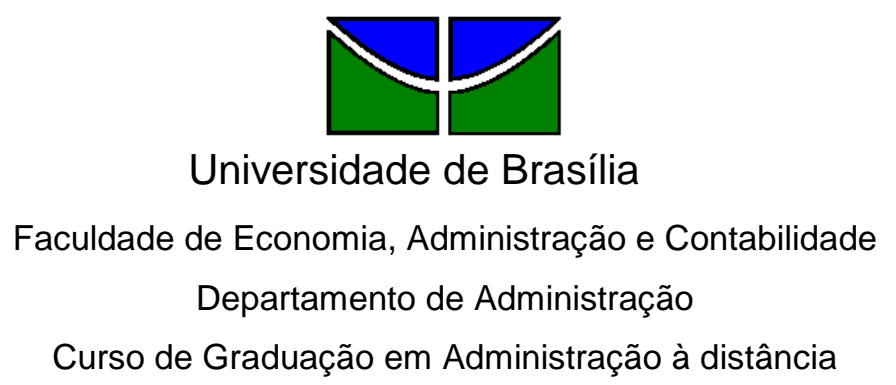

JOSÉ GERALDO ARAÚJO CALDAS

\title{
ESTRATÉGIA DRS - DESENVOLVIMENTO REGIONAL SUSTENTÁVEL: \\ A experiência no município de Paracatu MG
}

Brasília - DF 


\section{JOSÉ GERALDO ARAÚJO CALDAS}

\section{ESTRATÉGIA DRS - DESENVOLVIMENTO REGIONAL SUSTENTÁVEL: \\ A experiência no município de Paracatu MG}

Monografia apresentada a Universidade de Brasília (UnB) como requisito parcial para obtenção do grau de Bacharel em Administração.

Professor Orientador: Msc Marta Eliza de Oliveira

$$
\text { Brasília - DF }
$$


Caldas, José Geraldo Araújo.

Estratégia DRS - Desenvolvimento Regional Sustentável: a experiência no município de Paracatu MG / José Geraldo Araújo Caldas. - Brasília, 2010.

34 p. : il.

Monografia (bacharelado) - Universidade de Brasília, Departamento de Administração - EaD, 2010.

Orientador: Prof. Msc. Marta Eliza de Oliveira, Departamento de Administração.

1. Desenvolvimento Sustentável. 2. Responsabilidade social corporativa. 3. Importância das parcerias. 


\section{JOSÉ GERALDO ARAÚJO CALDAS}

\section{ESTRATÉGIA DRS - DESENVOLVIMENTO REGIONAL SUSTENTÁVEL: \\ A experiência no município de Paracatu MG}

A Comissão Examinadora, abaixo identificada, aprova o

Trabalho de Conclusão do Curso de Administração da Universidade de Brasília do aluno

\section{José Geraldo Araújo Caldas}

Msc Marta Eliza de Oliveira

Professor-Orientador

Mestre Fabrícia Faleiros Pimenta

Professor-Examinador
Doutora Selma Lúcia M. Gonzales

Professor-Examinador 
"A prática demonstra que um programa de responsabilidade social só traz resultados positivos para a sociedade e para a empresa se for realizado de forma autêntica. É necessário que a empresa tenha a cultura da responsabilidade social incorporada à sua visão de negócio." Oded Grajew 


\section{RESUMO}

Esta pesquisa teve o objetivo de analisar os impactos da implantação da estratégia DRS - Desenvolvimento Regional Sustentável, no município de Paracatu, em Minas Gerais. A estratégia proposta pelo Banco do Brasil, a partir de 2003, procura articular diversos atores sociais para apoiar e fortalecer uma determinada cadeia produtiva, no caso em estudo, a cadeia produtiva do leite. Os conceitos de Desenvolvimento Sustentável e Responsabilidade Social Corporativa são fundamentais para o embasamento teórico da discussão apresentada. A partir de uma articulação envolvendo os pequenos produtores, a COOPERVAP - Cooperativa Agropecuária do Vale do Paracatu, a Prefeitura Municipal, sindicatos rurais e EMATER - Empresa de Assistência Técnica e Extensão Rural do Estado de Minas Gerais, foi elaborado um plano de negócios prevendo objetivos a serem alcançados e respectivas ações necessárias. As entrevistas realizadas retrataram em que medida estes objetivos foram alcançados, e o que mudou na dia a dia dos pequenos produtores envolvidos. Para isto, foi utilizado o método exploratório com abordagem qualitativa, tendo sido estabelecido um roteiro para aplicação das entrevistas individuais. Constatou-se no presente trabalho, a possibilidade de se combinar os interesses negociais da empresa com ações que efetivamente tenham impactos socioambientais. Não obstante as limitações e deficiências da experiência em questão ficou demonstrado os seus efeitos positivos.

Palavras-chave: Desenvolvimento Sustentável. Responsabilidade Social Corporativa. Parceria. Produtividade. 


\section{LISTA DE TABELAS}

Tabela 1 - Métodos e abordagem da pesquisa: ........................................... 12

Tabela 2 - Motivos da participação na estratégia: ........................................... 16

Tabela 3 - Importância da Cooperativa: .......................................................... 17

Tabela 4 - Nível de acesso ao crédito: .......................................................... 18

Tabela 5 - Melhoria da qualidade de vida:......................................................... 19 


\section{LISTA DE ABREVIATURAS E SIGLAS}

DRS - Desenvolvimento Regional Sustentável

COOPERVAP - Cooperativa Agropecuária do Vale do Paracatu

AABB - Associação Atlética Banco do Brasil

UFU - Universidade Federal de Uberlândia

EMATER - Empresa de Assistência Técnica e Extensão Rural do Estado de Minas Gerais

PRONAF - Programa Nacional de Fortalecimento da Agricultura Familiar 


\section{SUMÁRIO}

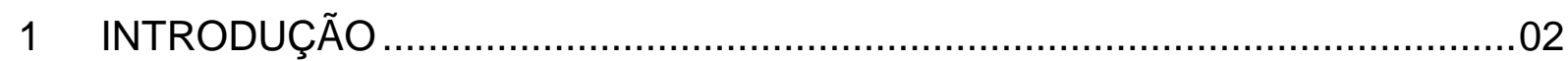

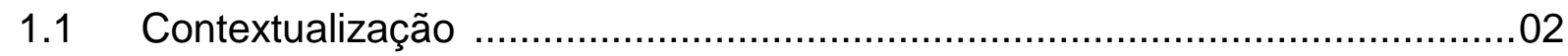

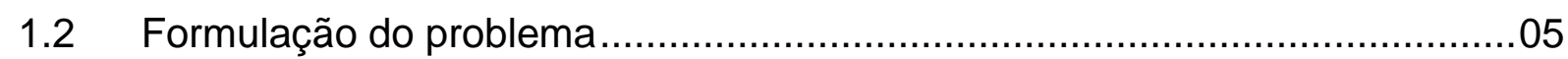

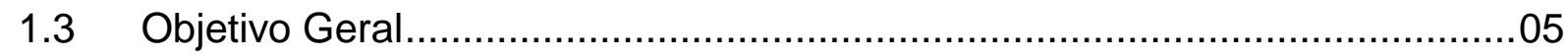

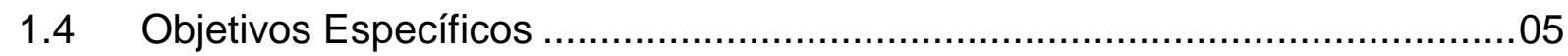

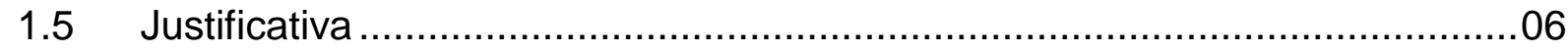

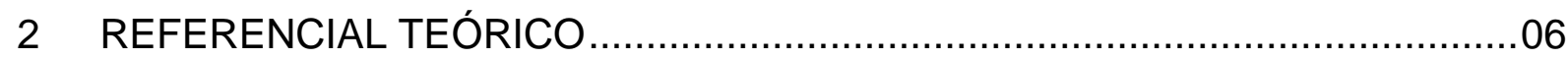

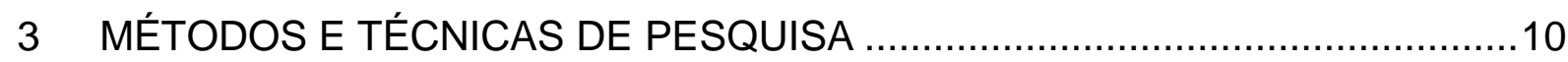

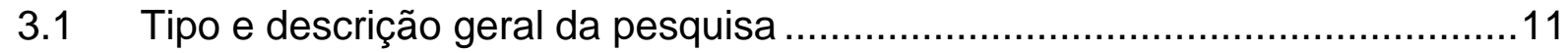

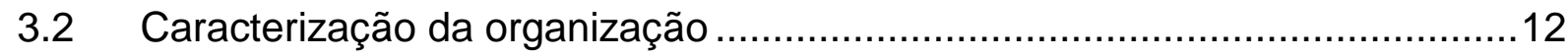

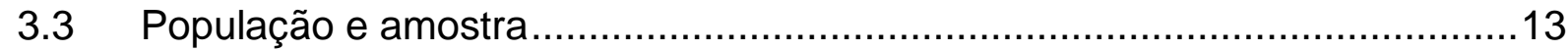

3.4 Caracterização do instrumento de pesquisa............................................14

3.5 Procedimentos de coleta e de análise de dados .......................................15

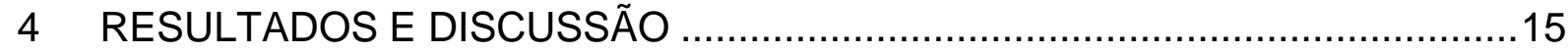

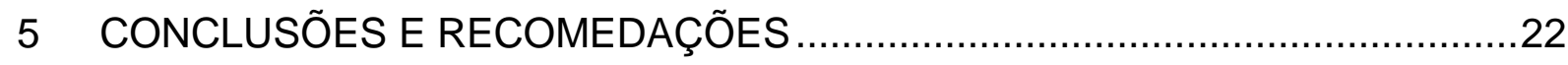

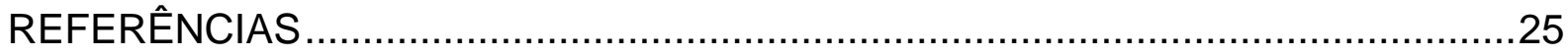

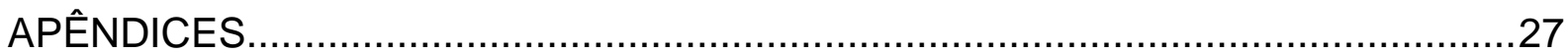

Apêndice A - Roteiro de entrevista - pequenos produtores ………………….....27

Apêndice B - Roteiro de entrevista - dirigente da cooperativa ................................29 


\section{INTRODUÇÃO}

\subsection{Contextualização}

O presente trabalho buscou relatar o resultado de pesquisa de campo para identificar os impactos na comunidade, das ações de responsabilidade social do Banco do Brasil, executadas com acompanhamento da agência local, no município de Paracatu MG, especialmente os impactos da implantação da estratégia DRS Desenvolvimento Regional Sustentável.

É importante considerar que a discussão acerca de um modelo de desenvolvimento que concilie resultados econômicos com responsabilidade socioambiental vem avançando ao longo do tempo.

Em 1987, o Relatório Brundtland, elaborado pela Comissão Mundial sobre Meio Ambiente e Desenvolvimento da ONU - Organização das Nações Unidas, liderada pela primeira-ministra da Noruega Gro Harlem Brundtland, definiu pela primeira vez o conceito de desenvolvimento sustentável. Desde então, o debate sobre a responsabilidade das pessoas e das organizações com o planeta e com a sociedade tem se aprofundado a ponto de assumir, hoje, papel estratégico fundamental nas políticas corporativas, conseqüência de um consumidor mais exigente e atento às questões sociais e ambientais.

Esta preocupação estratégica das organizações foi definida conceitualmente como Responsabilidade Social Corporativa. Segundo o Instituto Ethos (2007), responsabilidade social empresarial "é a forma de gestão que se define pela relação ética e transparente da empresa com todos os públicos com os quais ela se relaciona e pelo estabelecimento de metas empresariais compatíveis com 0 desenvolvimento sustentável da sociedade, preservando recursos ambientais e culturais para as gerações futuras, respeitando a diversidade e promovendo a redução das desigualdades sociais.".

Percebe-se que o conceito de responsabilidade social corporativa vai além da simples filantropia empresarial, pois se propõe a contribuir com a inclusão social a 
partir do foco na cadeia de negócios da empresa englobando preocupações com um público de relacionamento maior.

No Brasil, os anos 80 e 90 foram marcados por um baixíssimo crescimento, desemprego e inflação, o que agravou a má distribuição de renda, além de se registrar, no período, altos índices de desmatamento. Esse contexto impulsionou o movimento de valorização da responsabilidade socioambiental, inclusive nas instituições financeiras.

O Banco do Brasil, por sua vez, tem tradição em ações de cunho social, desde as iniciativas voluntárias do saudoso Betinho, com as campanhas de combate à fome até os projetos de educação e geração de emprego e renda financiados, com recursos não reembolsáveis, pela Fundação Banco do Brasil, passando pelo importante papel no financiamento da agricultura familiar através do PRONAF Programa Nacional de Fortalecimento da Agricultura Familiar.

No entanto, foi a partir de 2003 que o Banco do Brasil passou a incluir o assunto na pauta das decisões estratégicas e operacionais, com a criação de uma Unidade de Relações com Funcionários e Responsabilidade Socioambiental, transformada em 2004 na Diretoria de Relações com Funcionários e Responsabilidade Socioambiental.

Também neste período se intensificou as ações financiadas pela Fundação Banco do Brasil, sendo que no período de 2004 a 2006, se alcançou investimentos sociais anuais de mais de $\mathrm{R} \$ 100$ milhões, segundo dados disponibilizados no site da empresa (www.bb.com.br).

O estímulo governamental para avançar nas políticas sociais, a partir de 2003, produziu, também, outra revolução na forma de atuação do Banco do Brasil: o estabelecimento da estratégia negocial DRS - Desenvolvimento Regional Sustentável. Esta estratégia foca cadeias produtivas capazes de gerar renda, emprego e inclusão social, além de proporcionar negócios com um público com alta capacidade de fidelização. Até o final de março de 2010, 897.688 famílias já eram atendidas pela estratégia negocial, com alocação de recursos, pelo $\mathrm{BB}$, da ordem de mais de $\mathrm{R} \$ 5$ bilhões, segundo informações publicadas no site da empresa (www.bb.com.br). 
No município de Paracatu MG, localidade onde se realizará a pesquisa, a atuação do Banco do Brasil, nas questões sociais, no período de 2003 a 2010, também foi notadamente diferenciada em relação aos anos anteriores.

Vários projetos foram implantados ou fortalecidos com o apoio da Fundação Banco do Brasil, como:

- O Programa AABB Comunidade;

- A doação de três centros de inclusão digital;

- Duas pequenas agroindústrias (fábricas de farinha de mandioca) em dois assentamentos;

- Implantação da fábrica de vassouras ecológicas;

- Doação de caminhão para a Cooperativa de Catadores Paracatu Recicla, Criação de Ave Caipira;

- Fábrica de doces e biscoitos na Comunidade Quilombola do São Domingos do Paracatu, dentre outras.

Como se trata de um município considerado como uma importante bacia leiteira do estado de Minas Gerais, a implantação do DRS - Desenvolvimento Regional Sustentável, em Paracatu, focou a cadeia produtiva do leite, estabelecendo parceria do Banco do Brasil com a Cooperativa Agropecuária do Vale do Paracatu, a Emater - Empresa de Assistência Técnica e Extensão Rural do estado de Minas Gerais, o Sindicato dos Produtores Rurais, o Sindicato dos Trabalhadores Rurais e Prefeitura Municipal de Paracatu e Universidade Federal de Uberlândia.

São cerca de 120 as famílias participantes do DRS de Paracatu, denominado DRS Leite a Pasto. Estas famílias possuem acompanhamento de técnicos agropecuários que os visitam mensalmente, além da consultoria bimestral do Professor Edmundo Benedetti da UFU - Universidade Federal de Uberlândia, com orientações sobre o manejo correto para agregar valor e melhorar o resultado da atividade, além de conscientizar o produtor da importância de se estabelecer uma relação sustentável com o meio ambiente. 
A estratégia DRS, prevê a parceria com empresas que são chamadas de âncoras. Estas empresas compram o resultado da produção dos envolvidos na cadeia produtiva. No caso, a empresa que exerce este papel é a Cooperativa Agropecuária do Vale do Paracatu - Coopervap.

\subsection{Formulação do problema}

Considerando o propósito do presente trabalho, foi levantada a seguinte questão:

- Quais os impactos econômicos, sociais e ambientais das ações da estratégia DRS - Desenvolvimento Regional Sustentável do Banco do Brasil, implementadas no município de Paracatu, em Minas Gerais?

\subsection{Objetivo Geral}

O objetivo geral deste trabalho consiste na identificação dos impactos sociais e ambientais na comunidade, provenientes das ações da estratégia DRS Desenvolvimento Regional Sustentável, do Banco do Brasil, no município de Paracatu, em Minas Gerais.

\subsection{Objetivos Específicos}

A partir desse objetivo geral, pretendeu-se também:

- Avaliar a possível alteração de renda dos envolvidos;

- Identificar implantação de práticas conservacionistas;

- Verificar a efetividade das ações propostas;

- Demonstrar a importância das parcerias com entidades da sociedade civil. 


\subsection{Justificativa}

O mundo corporativo chega ao século XXI com o desafio de enfrentar a competitividade de uma economia globalizada, sem perder espaços ou reduzir resultados, mas ao mesmo tempo apresentando para a sociedade, alternativas que signifiquem avanços sociais associados a práticas conservacionistas.

Este cenário aprofundou a importância de se acompanhar os reflexos das ações sócio-ambientais das empresas, com o objetivo de revelar a efetividade dos seus resultados. Este acompanhamento pode diferenciar empresas que programam investimentos sociais de maneira eficiente e eficaz, como estratégia de crescimento e consolidação no mercado, ao mesmo tempo em que contribui com a inclusão social e a geração de renda, daquelas que utilizam o discurso do desenvolvimento sustentável apenas como instrumento de marketing.

Com a proposta de avaliar a efetividade da estratégia do Banco do Brasil, a partir das iniciativas da empresa no município de Paracatu MG, é que a presente pesquisa foi realizada.

\section{REFERENCIAL TEÓRICO}

São apresentados os aspectos teóricos afetos ao problema tratado, mediante uma revisão bibliográfica relativa ao desenvolvimento sustentável, responsabilidade social corporativa, papel dos bancos públicos e estabelecimento de parcerias.

\subsection{Desenvolvimento Sustentável}

Em 1987, a Comissão Mundial sobre Meio Ambiente e Desenvolvimento das Nações Unidas definiu, através de um relatório chamado de Our Common Future (Nosso 
Futuro Comum), o Desenvolvimento Sustentável como sendo o "modelo de desenvolvimento que atende às necessidades do presente sem comprometer a possibilidade de as gerações futuras atenderem às suas próprias necessidades”.

A partir deste conceito, o debate ambiental assumiu um novo patamar, permeando o discurso preservacionista com o reconhecimento da importância do desenvolvimento econômico e incorporando a este, mesmo que de maneira ainda incipiente, a inequívoca compreensão de que os limites naturais devem ser respeitados, para que as gerações futuras possam ter condições de também atender suas necessidades.

Todo conceito está sujeito a receber novas considerações teóricas que, algumas vezes contribui para sua consolidação e outras vezes, aponta suas contradições.

Para Fernandes (2003), o conceito de desenvolvimento sustentável, como hoje é apresentado à sociedade, acaba por obscurecer aquele que deveria ser o verdadeiro foco do debate atual em todos os aspectos e não apenas no ambiental, a saber, as diferenças, entre grupos sociais e entre nações, causadas pela atual forma de organização social de produção, ou seja, o atual sistema econômico de mercado.

Lima (2003) acrescenta que não há sustentabilidade possível sem a incorporação das desigualdades sociais e políticas e de valores éticos de respeito à vida e às diferenças culturais.

A amplitude do conceito de Desenvolvimento Sustentável permitiu sua associação com outros conceitos, dentre eles, o conceito de Responsabilidade Social Corporativa.

\subsection{Responsabilidade Social Corporativa}

Em 1988, o Conselho Empresarial Mundial para o Desenvolvimento Sustentável (World Business Council for Sustainable Development - WBCSD) concebeu o conceito de Responsabilidade Social Corporativa como: 
econômico, simultaneamente, à qualidade de vida de seus empregados e de seus familiares, da comunidade local e da sociedade como um todo".

Desde então, vários autores se dedicaram a discutir o conceito de responsabilidade social, evidenciando varias nuances. Apesar de ter sido confundida, por algum tempo, com a simples filantropia, a evolução e a consolidação do conceito de responsabilidade social corporativa ou empresarial, apontou para definições mais complexas.

Ashley, Coutinho e Tomei (2000) destacam que o conceito de responsabilidade social vem evoluindo quanto à capacidade de sua operacionalização e mensuração, subdividindo-se em diferentes vertentes de análise. Entre as vertentes estariam a responsabilidade social corporativa, o desempenho social corporativo, a atitude social corporativa, a auditoria social e inovação social.

De acordo com o Instituto Ethos, a Responsabilidade Social Empresarial é:

\begin{abstract}
"A forma de gestão que se define pela relação ética e transparente da empresa com todos os públicos com os quais ela se relaciona e pelo estabelecimento de metas empresariais que impulsionem o desenvolvimento sustentável da sociedade, preservando recursos ambientais e culturais para as gerações futuras, respeitando a diversidade e promovendo a redução das desigualdades sociais".
\end{abstract}

Carrol (1998) considera a responsabilidade social, um processo que deve envolver desde os acionistas, passando pelos funcionários, até a sociedade como um todo, incorporando quatro faces inter-relacionadas em constante tensão: econômica, legal, ética e filantrópica.

No tocante às práticas relacionadas com responsabilidade social, Melo (1999) destaca uma mudança no foco, passando pelas ações meramente filantrópicas até as ações mais substanciais que proporcionem desenvolvimento social.

Neste ponto surgem algumas divergências, pois, alguns autores entendem que as ações de responsabilidade social ocorrem em função da busca pelo lucro e não apenas pela motivação de maior justiça social.

Para Martinelli (1997) há organizações atuando no campo de responsabilidade social, ao visualizarem oportunidade de negócios. A base da argumentação mais crítica está na exposição das incoerências do capitalismo e sua lógica de 
acumulação. O discurso da responsabilidade social corporativa seria, então, uma maneira encontrada pelas organizações de se adequarem às novas exigências do mercado globalizado.

Para Srouz (1998, pag. 293) o que motiva as empresas a trocarem a simples maximização do lucro, pela busca do lucro com responsabilidade é o fato de que, como "as relações que amarram empresa e contrapartes são relações de poder", os stakeholders podem se mobilizar e retaliar a empresa que desrespeite normas básicas do trato com a sociedade.

Dessa forma, a verdadeira motivação para as práticas de responsabilidade social seria a busca de uma vantagem comparativa que resultará em um diferencial competitivo. Qualquer que seja a motivação, no entanto, o fato é que seja como discurso, ou como estratégia, a responsabilidade social vem aumentando gradativamente sua importância na vida organizacional.

\subsection{O papel dos bancos públicos e o estabelecimento de parcerias}

Com as instituições financeiras não é diferente. Diariamente elas tratam de um produto que é de importância fundamental para qualquer pessoa, empresas, e seus mais variados stakeholders: o dinheiro e seu valor.

Para Karkotli (2006, p.126) "os bancos públicos são em sua esfera de atuação, responsáveis pela promoção e desenvolvimento social nas regiões onde estão inseridos, entretanto para sua própria manutenção precisam gerar rentabilidade".

Fomentar o desenvolvimento regional é, portanto, um papel importantíssimo dessas instituições, promovendo o acesso a linhas de crédito e financiamentos ao setor produtivo rural e urbano. Para exercer esta função com a efetividade necessária é preciso absorver na sua estratégia os princípios da responsabilidade social.

Assim, um aspecto fundamental é a articulação e envolvimento dos interessados estabelecendo parcerias com outros setores, empresas, organizações governamentais e do terceiro setor. 
Para Grayson e Hodges (2003), o envolvimento efetivo das partes interessadas (stakeholders) requer um canal de comunicação aberto em ambas as direções, compromisso de gerentes e funcionários, participação ativa em políticas públicas, manutenção das parcerias, avaliação das necessidades da comunidade e compreensão da contribuição da empresa para atender a tais necessidades.

Já o Instituto Ethos (2006) define a parceria como:

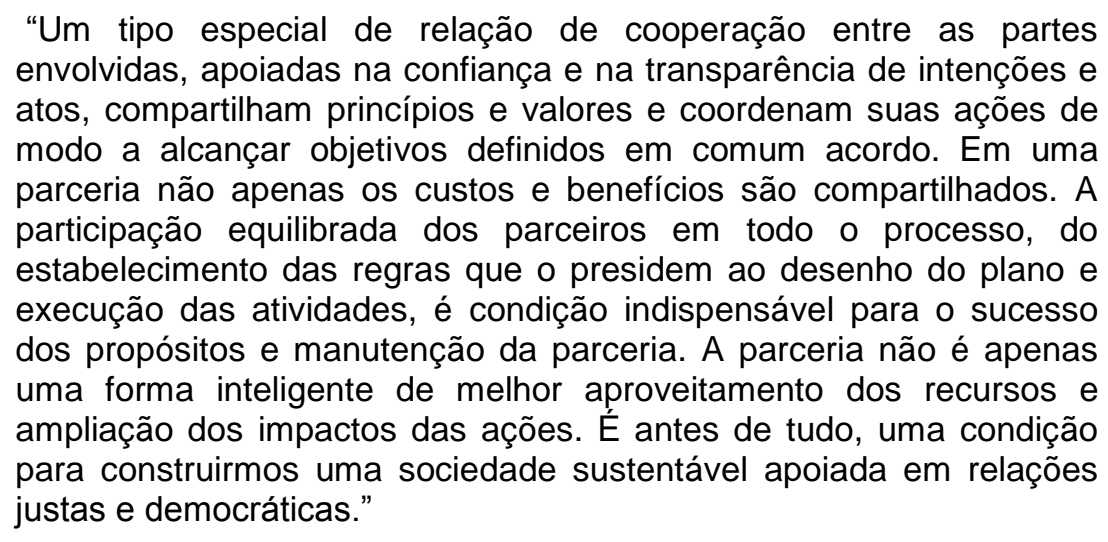

Com base na abordagem destes conceitos e considerações, encontra-se a fundamentação teórica para análise das experiências propostas na pesquisa.

\section{MÉTODOS E TÉCNICAS DE PESQUISA}

Neste tópico são apresentados os procedimentos metodológicos destacando a aplicação de questionários, entrevistas, analise documental, além da caracterização da organização e a definição dos participantes do estudo.

O presente estudo compreendeu uma ampla pesquisa bibliográfica sobre o tema proposto, levantamento de dados de fontes secundárias através de análise de documentos cedidos pela agência local do Banco do Brasil, bem como levantamento de campo por meio de entrevistas com os pequenos produtores rurais que participam da estratégia e de um dirigente da Coopervap - Cooperativa Agropecuária do Vale do Paracatu. 
Para Oliveira (1997), um método é um conjunto de processos pelos quais se torna possível conhecer uma determinada realidade, produzir determinado objeto ou desenvolver certos procedimentos ou comportamentos.

Fachin (2001), por sua vez, diz que o método científico caracteriza-se pela escolha de procedimentos sistemáticos para descrição e explicação de uma determinada situação sob estudo e sua escolha deve estar baseada em dois critérios básicos: a natureza do objetivo ao qual se aplica e o objetivo que se tem em vista no estudo.

\subsection{Tipo e descrição geral da pesquisa}

Foi realizada uma pesquisa do tipo exploratória que buscou conhecer os impactos e a efetividade da estratégia DRS nas comunidades pesquisadas, considerando a experiência da agência do Banco do Brasil do município de Paracatu MG.

Segundo Gil (1991), uma pesquisa exploratória visa proporcionar maior familiaridade com o problema com vistas a torná-lo explícito ou a construir hipóteses. Envolve levantamento bibliográfico; entrevistas com pessoas que tiveram experiências práticas com o problema pesquisado; análise de exemplos que estimulem a compreensão. Assume, em geral, as formas de Pesquisas Bibliográficas e Estudos de Caso.

Os dados para análise foram originados de pesquisa qualitativa, com aplicação de questionário aberto em entrevistas individuais realizadas nas propriedades rurais que aderiram à estratégia.

Os dados secundários foram obtidos através de pesquisa bibliográfica e análise documental. A análise documental foi feita em consulta a dados fornecidos pela empresa âncora da estratégia, a Cooperativa Agropecuária do Vale do Paracatu e também a partir de dados fornecidos pela agência local do Banco do Brasil.

A tabela 1 contempla o detalhamento do método e da abordagem que foram utilizados na pesquisa, relacionando-os aos objetivos específicos do trabalho. 
Tabela 1 - Métodos e abordagem da pesquisa

\begin{tabular}{|l|l|l|}
\hline \multicolumn{1}{|c|}{ Objetivos Específicos } & Método & Abordagem \\
\hline $\begin{array}{l}\text { 1-Avaliar a possível alteração de renda } \\
\text { dos envolvidos. }\end{array}$ & Exploratório & Qualitativa \\
\hline $\begin{array}{l}\text { 2- Identificar implantação de práticas } \\
\text { conservacionistas }\end{array}$ & Exploratório & Qualitativa \\
\hline $\begin{array}{l}\text { 3- Verificar a efetividade das ações } \\
\text { propostas }\end{array}$ & Exploratório & Qualitativa \\
\hline $\begin{array}{l}\text { 4- Demonstrar a importância das } \\
\text { parcerias com entidades da sociedade } \\
\text { civil }\end{array}$ & Exploratório & Qualitativa \\
\hline
\end{tabular}

\subsection{Caracterização da organização}

A empresa pesquisada é o Banco do Brasil. A empresa foi escolhida porque tem forte atuação no município de Paracatu MG em ações de responsabilidade social, além de ser a empresa onde trabalho.

Criado em outubro de 1808 , através de um alvará do príncipe regente D. João, o Banco do Brasil possui hoje mais de quatro mil agências e mais de 40 mil caixas eletrônicos. É a maior instituição financeira do país. Na atual composição societária da empresa, o Tesouro Nacional detém $51,8991 \%$ das ações, conforme informações disponíveis no site da empresa (www.bb.com.br). 
A missão da empresa é: "Ser a solução em serviços e intermediação financeira, atender às expectativas de clientes e acionistas, fortalecer o compromisso entre os funcionários e a Empresa e contribuir para o desenvolvimento do País".

Com mais de 80 mil funcionários, o Banco do Brasil tem uma atuação reconhecida na área social, principalmente através da Fundação Banco do Brasil. A partir de 2003 com a implantação da estratégia DRS - Desenvolvimento Regional Sustentável, o Banco passou a atuar no fortalecimento de cadeias produtivas de maneira sistematizada e articulada com outras organizações privadas, públicas e do terceiro setor, considerando sempre os princípios da sustentabilidade.

Ainda conforme informações disponibilizadas no site da empresa:

\footnotetext{
"A metodologia de atuação prevê a sensibilização, mobilização e capacitação de funcionários do BB e de parceiros, e ainda a elaboração de um amplo diagnóstico, sendo abordada a cadeia de valor das atividades produtivas apoiadas e identificados pontos fortes, pontos fracos, oportunidades, ameaças e potencialidades, dentre outros".
}

A pesquisa foi realizada na agência de Paracatu/MG, cidade localizada a $200 \mathrm{~km}$ de Brasília. Esta agência, aberta ao público em 1955, possui atualmente 37 funcionários e é a maior agência bancária da cidade.

\subsection{População e amostra}

A estratégia DRS no município de Paracatu envolve 120 pequenos produtores divididos em oito regiões da zona rural. Em cada uma destas regiões existe uma unidade modelo.

Para cada unidade modelo existem vários produtores chamados de unidades satélites, que se reúnem bimestralmente na unidade modelo para assistirem palestras e avaliarem os resultados obtidos.

O DRS - Desenvolvimento Regional Sustentável é coordenado por uma equipe formada pelos parceiros, tendo à frente a Cooperativa Agropecuária do Vale do 
Paracatu. Esta cooperativa é chamada de "empresa âncora", pois adquire toda a produção dos produtores, além de prestar o serviço de assistência técnica.

Foi realizada uma amostragem não probabilística por julgamento, correspondendo ao total das unidades modelo, ou seja, oito produtores e mais um produtor satélite de cada uma destas unidades. Assim, a pesquisa atingiu dezesseis pessoas, além do dirigente da empresa âncora, a Cooperativa Agropecuária do Vale do Paracatu.

Os produtores das unidades modelos são importantes para a pesquisa, à medida que representam, em tese, o objetivo da estratégia. Os satélites são significativos porque representam a realidade da maioria dos produtores envolvidos e retratam em que velocidade assimilam as mudanças propostas e como as ações propostas evoluem no cotidiano das comunidades.

Os entrevistados foram escolhidos a partir de uma listagem cedida pela Coopervap Cooperativa Agropecuária do Vale do Paracatu, contendo o nome dos proprietários das unidades demonstrativas e os proprietários das unidades demonstrativas vinculados a cada uma das unidades demonstrativas.

O dirigente da empresa âncora, a Cooperativa Agropecuária do Vale do Paracatu, demonstrou a percepção da empresa quanto ao desenvolvimento econômico e social dos participantes da estratégia DRS.

\subsection{Instrumento de pesquisa}

O instrumento de pesquisa utilizado foi um questionário com perguntas abertas, sendo um questionário para os pequenos produtores e outro para o dirigente da "empresa âncora", aplicados em entrevistas individuais, conforme demonstrado no APÊNDICE A e APÊNDICE B. 


\subsection{Procedimentos de coleta e de análise de dados}

A coleta dos dados primários foi realizada através de entrevistas individuais, com aplicação do questionário detalhado nos apêndices A e B. As entrevistas foram gravadas e transcritas posteriormente.

Os dados secundários foram coletados através de análise de documentos disponibilizados pela agência do Banco do Brasil de Paracatu e pela empresa parceira COOPERVAP - Cooperativa Agropecuária do Vale do Paracatu.

A agência local do Banco do Brasil disponibilizou o plano de negócios elaborado em conjunto com os parceiros, contendo os objetivos e as ações planejadas.

Kerlinger (1980, pag.353), define o processo de análise de dados como "a categorização, ordenação, manipulação e sumarização de dados". Dessa forma, é fundamental para que os dados sejam interpretados e compreendidos.

Como processo de análise de dados, foi utilizado análise estatística e análise de conteúdo.

Minayo (2003, p. 74), enfatiza que "a análise de conteúdo visa verificar hipóteses e ou descobrir o que está por trás de cada conteúdo manifesto".

A análise de conteúdo é considerada uma técnica para o tratamento de dados que visa identificar o que está sendo dito a respeito de determinado tema (Vergara, 2005, p.15).

\section{RESULTADOS E DISCUSSÃO}

A pesquisa foi realizada buscando os objetivos específicos e o objetivo geral a partir de entrevistas com três grupos que representam os atores envolvidos na estratégia DRS - Desenvolvimento Regional Sustentável: as unidades demonstrativas, totalizando oito entrevistados, uma amostra das unidades satélites, também somando oito entrevistados e a empresa âncora, a Cooperativa Agropecuária do 
Vale do Paracatu. Antes, porém, destas entrevistas foi realizado um levantamento documental para averiguar os principais objetivos estabelecidos no plano de negócios da estratégia DRS - Desenvolvimento Regional Sustentável apresentado pela agência do Banco do Brasil de Paracatu MG e pelos parceiros.

No documento em questão constam como principais objetivos:

1- Aumentar a produtividade média;

2- Elevar a margem de ganho dos produtores;

3- Capacitar produtores

4- Melhorar infraestrutura de produção

5- Reforçar e estimular cultura associativista

6- Aumentar a produção de leite

7- Reduzir custos operacionais

8- Implantar técnicas de conservação ambiental

9- Reduzir o analfabetismo

10-Aumentar o atendimento as demandas de crédito

Para cada um dos objetivos, foram definidas várias ações necessárias.

A realização das entrevistas buscou levantar informações que pudessem constatar se tais objetivos estão sendo alcançados.

Inicialmente, foi possível verificar que duas razões motivaram a participação dos produtores na estratégia: expectativa ou oportunidade de melhorias na atividade e convite ou convencimento por parte da Cooperativa. Na tabela 2, verifica-se como se dividiram estas duas ocorrências.

\begin{tabular}{|l|l|}
\hline Motivo da participação & Quantidade de produtores \\
\hline $\begin{array}{l}\text { Expectativa ou oportunidade de } \\
\text { melhorias }\end{array}$ & 9 \\
\hline Convite ou convencimento & 7 \\
\hline Tabela 2 - Motivos da participação na estratégia
\end{tabular}


A estratégia DRS - Desenvolvimento Regional Sustentável prevê a existência de uma empresa âncora, ou seja, uma empresa que funciona como um pivô de toda a atividade. No caso em estudo, uma empresa que vende insumos para os produtores e se dispõe a comprar toda a produção deles. A pesquisa buscou saber qual a importância desta empresa para o sucesso da estratégia. A resposta com maior ocorrência foi a prestação de serviços de assistência técnica. Esta resposta se fez notar principalmente entre as unidades demonstrativas ou modelos, sendo que todos os entrevistados nesta situação citaram este aspecto como o mais importante. Certamente, o motivo para esta predominância da resposta está no fato de que a cooperativa contratou vários técnicos agropecuários para prestar assistência técnica periódica para todos os participantes da estratégia DRS - Desenvolvimento Rural Sustentável. Na tabela 3 e no gráfico 1 estão registradas todas as ocorrências.

\begin{tabular}{|l|l|}
\hline Importância da Cooperativa & Produtores \\
\hline Assistência técnica & 11 \\
\hline Estabelecimento de parcerias & 02 \\
\hline Compra de toda a produção & 01 \\
\hline Ajuda no desenvolvimento da atividade & 01 \\
\hline Fonte de financiamento & 01 \\
\hline
\end{tabular}

Tabela 3 - Importância da Cooperativa

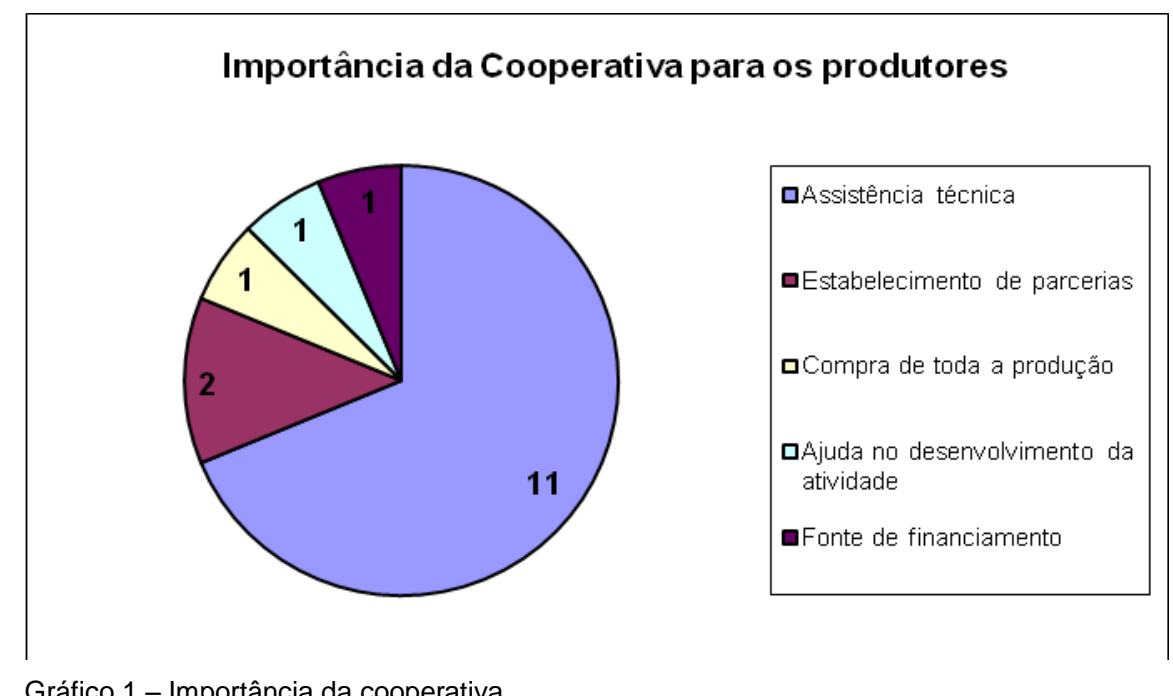

Gráfico 1 - Importância da cooperativa

O exercício da atividade da bovinocultura do leite tem o crédito como uma importante variável. A pesquisa revelou o nível de acesso ao crédito e a expectativa dos produtores em relação a este acesso. Todos os produtores entrevistados 
desejam contratar algum empréstimo para financiar a atividade. No entanto, a maioria nunca contratou nenhum empréstimo em nenhuma instituição financeira. Percebe-se nesta resposta, que os pequenos produtores ainda têm alguma dificuldade para terem acesso ao crédito. No entanto, três destes produtores que nunca contrataram empréstimos disseram já estar providenciando documentação para entregarem proposta de financiamento na agência do Banco do Brasil, o que pode sinalizar o início de uma mudança da realidade atual. Na tabela 4 está descrito o nível de acesso ao crédito.

\begin{tabular}{|l|l|}
\hline $\begin{array}{l}\text { Já contratou algum } \\
\text { empréstimo? }\end{array}$ & Produtores \\
\hline Não & 10 \\
\hline Sim & 06 \\
\hline \multicolumn{2}{|l|}{ Tabela 4 - Nível de acesso ao crédito }
\end{tabular}

O objetivo da estratégia DRS - Desenvolvimento Regional Sustentável é melhorar a qualidade de vida das pessoas da comunidade em que a empresa está inserida. Como está a percepção dos atores envolvidos quanto a esta questão?

A pesquisa revelou que todos os entrevistados percebem, em alguma medida, a melhoria da sua qualidade de vida. No entanto, alguns aspectos importantes no plano de negócios firmado pelos parceiros não foram percebidos pelos produtores. O principal deles é a educação. Nenhum dos entrevistados citou este aspecto como algo que tenha melhorado, revelando que um dos objetivos estabelecidos no plano de negócios não foi perseguido como esperado. Seis dos entrevistados vincularam a melhoria da qualidade de vida com a aquisição de algum bem de consumo, principalmente eletrodomésticos ou eletrônicos. Dos seis produtores que adquiriram um bem novo, um deles comprou um computador, utilizado, dentre outras coisas, para gerenciar melhor a atividade leiteira. Os entrevistados que abordaram a melhoria na higiene e na saúde, atribuem tal melhoria às palestras e orientações dos técnicos. A parceria da Prefeitura na estratégia foi, segundo três dos entrevistados, o motivo para a melhoria de estradas e dos serviços prestados como silagem e outros.

$\mathrm{Na}$ tabela 4 estão relacionadas as respostas encontradas para esta questão e no gráfico 2 está ilustrada esta distribuição. 


\begin{tabular}{|l|l|}
\hline Melhoria de qualidade de vida & Produtores \\
\hline Adquiriu algum bem novo & 06 \\
\hline Mais higiene & 06 \\
\hline Mais saúde & 02 \\
\hline $\begin{array}{l}\text { Melhor prestação de serviços da } \\
\text { Prefeitura }\end{array}$ & 02 \\
\hline Estradas melhores & 01 \\
\hline Melhor relacionamento familiar & 01 \\
\hline
\end{tabular}

Tabela 5 - Melhoria de qualidade de vida

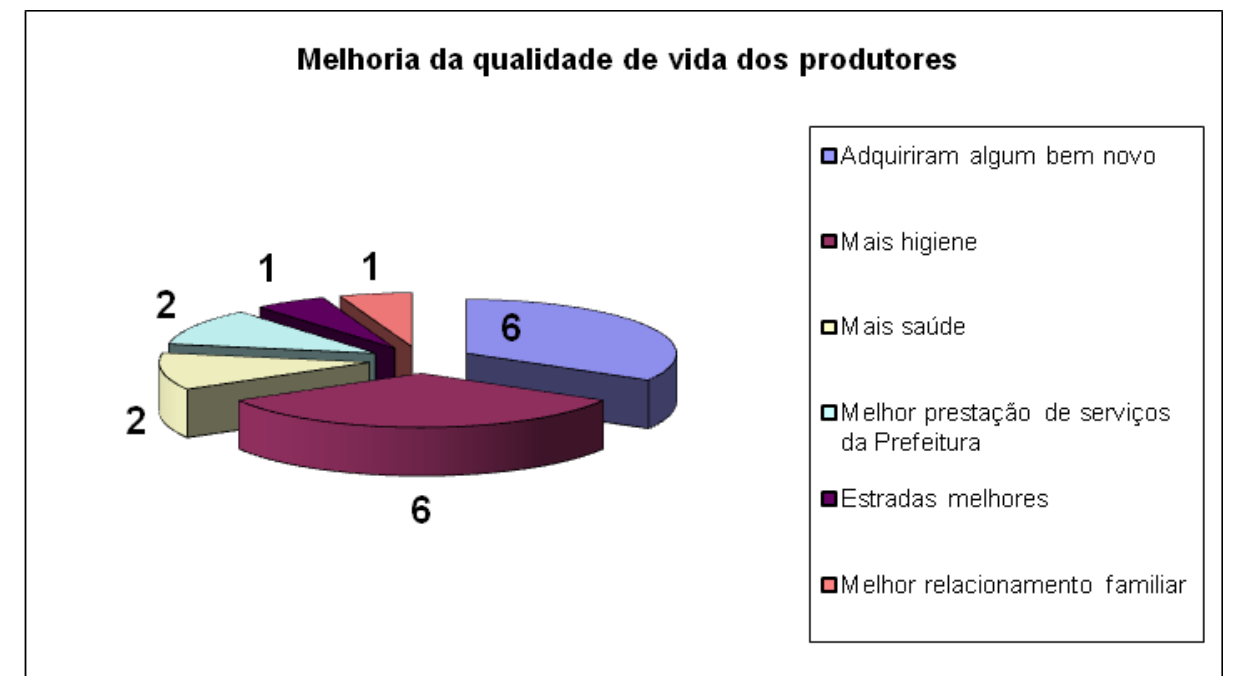

Gráfico 2 - Qualidade de vida

Um dos pontos mais importantes da estratégia é a preservação ambiental. Este é um dos pilares do Desenvolvimento Sustentável. No entanto, apesar de todos os entrevistados considerarem importante a preservação ambiental, apenas seis produtores adotam alguma prática conservacionista. E todos eles são unidades modelo. Dentre aqueles que possuem uma nascente no terreno, apenas metade providenciaram o seu fechamento. As respostas revelam avanços ainda tímidos, significando um dos desafios a serem enfrentados pelos parceiros e pelos próprios produtores.

Dos três pilares do Desenvolvimento Sustentável, o social, o ambiental e o econômico, este último foi o mais observado pelos entrevistados. Quando questionados sobre a alteração de renda, todos responderam que houve aumento de renda. Apenas um entrevistado considerou este aumento pequeno. A variação positiva da renda foi atribuída ao aumento da produção e da produtividade, bem como do melhor preço pago pelo leite em função da melhoria da qualidade do 
produto. Percebe-se também neste aspecto que, a melhoria da renda é reconhecida com mais intensidade nas unidades demonstrativas, inclusive com alguns entrevistados citando índices ou valores.

A pesquisa buscou também saber a percepção da empresa âncora, no caso, a Cooperativa tem sobre a estratégia DRS - Desenvolvimento Regional Sustentável.

Neste sentido, foi entrevistado um dos diretores da empresa. Seguindo o roteiro da entrevista apresentado no projeto, foi possível verificar basicamente dois aspectos, as parcerias e a variação na produção e na produtividade.

Quanto às parcerias, o entrevistado destaca que a estratégia só está sendo viabilizada em função do envolvimento de parceiros, como o Banco do Brasil, a Prefeitura, a EMATER e o Sindicato Rural. Ele afirma que "quando cada um assume sua responsabilidade e se empenha pra conseguir um objetivo comum, o sucesso de qualquer iniciativa é só uma questão de tempo".

O diretor confirma que a relação entre os parceiros tem se mostrado cada vez mais consolidada e que a sintonia entre as ações realizadas pelos parceiros têm promovido vários avanços para o pequeno produtor de leite.

Segundo o diretor, a empresa ainda não possui um relatório detalhado e consolidado acerca da variação da produção e da produtividade desde o início da estratégia DRS - Desenvolvimento Regional Sustentável.

No entanto, é possível afirmar, segundo ele, que todas as unidades demonstrativas obtiveram aumento na produção acima de 50\% (cinqüenta por cento) e que a produtividade também melhorou muito. Já nas unidades satélites, apesar de ser possível identificar fortes variações em alguns casos, em outros ainda não é possível fazer a mesma afirmação. Isto porque, segundo ele, alguns produtores ainda resistem a seguir todas as orientações técnicas repassadas.

Os dados levantados permitem avaliar os impactos da implantação da estratégia DRS - Desenvolvimento Regional Sustentável no município de Paracatu MG. Partindo do conceito de Desenvolvimento Sustentável, que se baseia em pilares como o econômico, o social e ambiental, percebe-se no plano de negócios, ações que contemplam as três visões. 
Sempre que se submetem ações de Responsabilidade sócio-ambiental a qualquer análise, recomeça a discussão se tais ações são executadas com o objetivo de contribuir com a comunidade no sentido de dotar o modelo de desenvolvimento de características sustentáveis ou se trata apenas de estratégia mercadológica. As posições de diversos autores são conflitantes ao debater este tema. No entanto, existem casos que permitem que diferentes visões se convirjam.

A dicotomia entre o interesse mercadológico e o interesse na contribuição para um modelo de desenvolvimento efetivamente sustentável, não é insuperável.

Martinelli (1997) relaciona a responsabilidade social com oportunidade negocial, em função de novas exigências do mercado globalizado. Também neste sentido, Srouz (1998) anota a preocupação das empresas com os stakeholders que podem se mobilizar e retaliar aquelas organizações que não respeitem normas básicas no trato com a sociedade.

Por fim, o Instituto Ethos destaca a Responsabilidade Social Empresarial como uma forma de gestão onde a organização se relaciona de maneira ética e transparente com todos os públicos com os quais se relaciona.

A estratégia DRS - Desenvolvimento Regional Sustentável pode ser uma maneira de atuação que contempla o aspecto negocial, já que amplia o volume de negócios do publico alvo com a empresa e uma maneira de contribuir com um modelo sustentável de desenvolvimento.

Nos dados levantados e nas respostas dos entrevistados não é difícil de observar que existe um grande potencial negocial, já que todos manifestaram desejo de contratar um empréstimo para financiar a atividade. A bancarização deste público pode ainda gerar outros negócios.

Por outro lado, percebe-se que a implantação da estratégia possibilitou uma melhoria na qualidade de vida dos envolvidos, inclusive com mudanças na maneira de trabalhar, gerando custos menores e maior produção, com a conseqüente melhoria da renda. Um ponto que ficou evidente foi a importância das parcerias neste processo. 
Enquanto Carrol (1998) relaciona a responsabilidade social com o envolvimento dos funcionários e da sociedade como um todo, o Instituto Ethos (2006) reforça a importância das parcerias destacando que "a participação equilibrada dos parceiros em todo o processo, do estabelecimento das regras que presidem ao desenho do plano a execução das atividades, é condição indispensável para o sucesso dos propósitos e manutenção da parceria."

Sob este aspecto, é possível verificar nas informações levantadas que a definição do plano de negócios com suas respectivas ações foram definidas e executadas envolvendo a parceria do Banco do Brasil, Prefeitura Municipal, Emater MG, Sindicato Rural e a Coopervap - Cooperativa Agropecuária do Vale do Paracatu. O relato do diretor da Cooperativa e algumas respostas dos entrevistados demonstraram a importância destas parcerias para o sucesso da estratégia proposta.

\section{CONCLUSÕES E RECOMENDAÇÕES}

Este estudo teve o objetivo principal de verificar os impactos da estratégia DRS Desenvolvimento Regional Sustentável, focada na cadeia produtiva do leite, no município de Paracatu-MG.

Com esta estratégia, a empresa propõe aplicar os conceitos de responsabilidade socioambiental de maneira efetiva, indo além do marketing verde ou do marketing social.

A proposta é transformar as ações socialmente responsáveis e ambientalmente corretas em algo que possa ao mesmo tempo promover mudanças na qualidade de vida das pessoas, ampliar a geração de negócios e dotá-los de sustentabilidade. Para isto, prevê a articulação e a parceria entre o Banco, empresas privadas, organizações do terceiro setor e Poder Público.

Percebe-se nos resultados apresentados, que a estratégia tem atingido grande parte dos objetivos propostos, principalmente a melhoria de renda dos pequenos produtores. Esta alteração positiva foi observada em todas as entrevistas realizadas, com intensidade variada, mas sempre de maneira significativa. 
Os ganhos econômicos são, portanto, o primeiro impacto percebido pelos participantes da estratégia, devido ao aumento de produção e produtividade, resultado das orientações dos técnicos e do consultor contratados pela empresa âncora, Cooperativa Agropecuária do Vale do Paracatu.

Por outro lado, os avanços sociais observados parecem estar mais ligados a alteração da renda. A percepção dos produtores acerca deste tema está mais no acesso a bens de consumo, apesar de se observar importes considerações sobre melhorias quanto à higiene e saúde. Nota-se, contudo, que não há impacto na escolaridade das famílias em função da estratégia, embora o plano de negócios preveja ações neste sentido. Apesar disto, houve alguma melhoria na questão das estradas e da assistência da patrulha (tratores e maquinas), em função da parceria da Prefeitura Municipal de Paracatu.

O terceiro pilar da sustentabilidade, a questão ambiental, é certamente a que se observaram impactos mais tímidos. Embora todos os entrevistados tenham atribuído importância ao tema, a minoria sabe o que precisa ser feito e poucos produtores já desenvolveram alguma ação ambientalmente necessária, como proteção de nascentes, recuperação de áreas degradas, etc.

Apesar disto, é inegável que a estratégia DRS - Desenvolvimento Regional Sustentável inseriu esta temática no dia a dia do pequeno produtor, com percepção maior nas unidades demonstrativas.

Não obstante estas considerações, ao confrontar os principais objetivos estabelecidos na estratégia, com os resultados observados, é possível perceber que a maioria está sendo alcançada.

Pelos dados levantados na pesquisa, é possível afirmar que existe uma convergência entre os interesses negociais das empresas e organizações envolvidas com as expectativas dos pequenos produtores quanto a melhorias na qualidade de vida.

Portanto, ao responder ao problema da pesquisa, cabe ressaltar dentre os impactos da estratégia na comunidade, o aumento significativo da renda dos pequenos produtores, a capacitação para o desenvolvimento da atividade proporcionada pelas orientações técnicas, a maior possibilidade de acesso ao crédito, o início de uma 
conscientização para o enfrentamento dos problemas ambientais e o fortalecimento das parcerias.

No entanto, a pesquisa permite também concluir que, no caso estudado, ainda se faz necessário avançar além das melhorias de produtividade, produção e renda.

É compreensível que estes aspectos assumam importância mais imediata para os envolvidos, já que representam a principal finalidade de uma atividade econômica em sociedades capitalistas. Contudo, a continuidade da estratégia como uma ação efetiva de responsabilidade socioambiental depende da consistência de avanços sociais e ambientais mais significativos. É imprescindível oferecer alternativas que signifiquem a possibilidade de acesso à educação, além de intensificar a demonstração da importância da preservação ambiental para a sustentabilidade da atividade.

Apesar do esforço da pesquisa, é importante ressaltar que, este estudo não teve a pretensão de avaliar a estratégia DRS - Desenvolvimento Regional Sustentável, de uma maneira geral, já que está limitada a experiência do município de Paracatu MG, mas permite a partir de uma experiência local, levantar um debate sobre a importância de iniciativas empresariais que promovam 0 desenvolvimento sustentável das comunidades em que atua, bem como seus desafios e suas limitações.

Finalmente, a pesquisa permite afirmar que os impactos da estratégia DRS Desenvolvimento Regional Sustentável têm melhorado a qualidade de vida dos pequenos produtores de leite das regiões do município que aderiram à proposta, e com isso demonstrar que é possível convergir interesses negociais da empresa com ações efetivas de responsabilidade social empresarial.

Esta convergência representa, na verdade, o grande desafio que está colocado para as organizações que ousam atuar em um mercado altamente competitivo sem abrir mão de resultados crescentes, mas também sem perder a noção de sua responsabilidade para a construção de uma sociedade que avance continuadamente nas questões sociais e ambientais.

Para vencer este desafio fica claro que é preciso diagnosticar corretamente a realidade, estabelecer parcerias, planejar e atuar com a determinação e 
responsabilidade necessária para alcançar os objetivos empresariais e ao mesmo tempo ser agente de mudanças na comunidade em que a organização está inserida.

\section{REFERÊNCIAS BIBLIOGRÁFICAS}

ASHLEY, P. A., COUTINHO, R. B. G., \& Tomei, P. A. Responsabilidade social corporativa e cidadania empresarial: uma análise conceitual comparativa. Anais do Encontro Nacional da Associação Nacional de Pós-Graduação e Pesquisa em Administração, Florianópolis, SC, Brasil, 2000.

BRASIL. BANCO DO BRASIL. Disponível em: <http://www.bb.com.br>. Acesso em 17/08/2010.

Comissão Mundial Sobre Meio Ambiente e Desenvolvimento, Our Common Future. Oxford: Oxford University Press, 1987

INSTITUTO ETHOS. Disponível em < http://www.ethos.org.br>. Acesso em 19/08/2010.

INSTITUTO EHTOS. Responsabilidade Social Empresarial nos Processos Gerenciais e nas Cadeias de Valor. São Paulo, 2006

CARROLL, A. B. The four faces of corporate citizenship. Business and society review, 100(101), 1-7, 1998.

FACHIN, Odília. Fundamentos de metodologia. São Paulo: Saraiva, 2001

FERNANDES, Marcionila. Desenvolvimento Sustentável: Antinomias de um conceito. Belém: AUA, 2003.

GRAYSON, David. HODGES, Adrian. Compromisso social e gestão empresarial. 1 ed. São Paulo: Publifolha, 2003.

GIL, Antonio Carlos. Como elaborar projetos de pesquisa. São Paulo: Atlas, 1991. KARKOTLI, Gilson. Responsabilidade social empresarial. 1. ed. Petrópolis: Vozes, 2006.

KERLINGER, F.N. Metodologia da pesquisa em ciências sociais. Tradução de H.M. Rotundo. São Paulo e Brasília: EPU-EDUSP e INEP, 1980.

LIMA, Gustavo da Costa. "O discurso da sustentabilidade e suas implicações para a educação". In: Ambiente e sociedade. São Paulo: Unicamp, v.6, n.2, jul./dez.2003. 
MELO, F. P. Neto. Responsabilidade social e cidadania empresarial: a administração do terceiro setor. Rio de Janeiro: Qualitymark, 1999.

MARTINELLI, A. C.. Empresa cidadã. In: $3^{\circ}$ setor: desenvolvimento social sustentado. E. loschpe (pp. 81-88). Rio de Janeiro: Paz e Terra, 1997

MINAYO, M.C. de S. (Org..). Pesquisa social: teoria, método e criatividade. 22. ed. Rio de Janeiro: Vozes, 2003

OLIVEIRA, Silvio Luiz de. Tratado de metodologia científica. São Paulo: Pioneira, 1997

SROUR, Robert Henry. Poder, cultura e ética nas organizações. Rio de Janeiro: Campus, 1998.

VERGARA, Sylvia Constant. Métodos de pesquisa em Administração. São Paulo: Atlas, 2005. 


\section{APÊNDICES}

\section{APÊNDICE A}

\section{Pequenos produtores}

1) Porque você aderiu ao DRS Leite a pasto?

Nesta questão pretende-se identificar a motivação do produtor para participar da estratégia DRS.

2) Qual importância você atribui ao papel da Cooperativa na implantação do DRS?

Essa questão permite saber a importância de uma empresa âncora na estratégia.

3) Você possui ou já possuiu algum empréstimo rural contratado em uma instituição financeira?

Esta questão tem o objetivo de avaliar o nível atual de bancarização e acesso ao crédito dos participantes do estudo.

4) Você pretende investir em novos equipamentos e/ou renovação do rebanho para aumentar a produção e a produtividade?

Esta pergunta possibilitará verificar a expectativa de investimento e crescimento dos produtores.

5) O DRS Leite a Pasto provocou mudanças no seu dia a dia que possibilitaram uma melhor qualidade de vida? (Ex: alfabetização, noções de higiene, saúde preventiva, aquisição de novos bens de consumo, etc.)

Nesta questão pretende-se verificar se a estratégia trouxe algum dado que possibilite verificar alterações na qualidade de vida

6) Você considera importante a questão ambiental? Adotou alguma prática de proteção ambiental na propriedade? (Ex: proteção de nascentes, recuperação de área degradada, proteção do solo, etc.) 
Este item pode revelar se o DRS provocou alguma mudança de postura em relação ao meio ambiente e o nível de conscientização dos produtores.

7) Sua renda teve alguma alteração desde a adesão ao DRS Leite a Pasto?

O objetivo é verificar o impacto da estratégia na renda do produtor.

Como a cooperativa é o único comprador dos produtores, esta questão pode revelar o impacto da estratégia na relação com os produtores. 


\section{APÊNDICE B}

\section{Dirigente da Cooperativa Agropecuária do Vale do Paracatu}

1) Que importância a empresa atribui a parceria que resultou na implantação e no desenvolvimento da estratégia Leite a Pasto?

Esta questão definirá a visão que a empresa tem da estratégia

2) Qual a variação já percebida na produção e na produtividade dos cooperados participantes do Leite a pasto?

Esta questão mostrará o impacto da estratégia na produção e na produtividade

3) Como a empresa vê a relação entre os parceiros na estratégia?

O objetivo é verificar a efetividade das parcerias

4) Quais as mudanças que a estratégia provocou na relação da empresa com os cooperados envolvidos? 